\title{
A noção de valores biológicos em Nietzsche
}

\author{
Emmanuel Salanskis*
}

Resumo: Este artigo visa a esclarecer o uso concreto que Nietzsche faz do vocabulário biológico em sua obra. Em vez de conceber a biologia como a soma indiferenciada das ciências da vida, o que é um anacronismo em vista da situação fragmentada dessas ciências na segunda metade do século XIX, levo em consideração o trabalho de Lynn Nyhart sobre a ascensão da perspectiva biológica na Alemanha, para evidenciar o sentido mais estreito no qual Nietzsche fala de "biologia". A primeira parte do artigo identifica os interlocutores que Nietzsche caracteriza explicitamente como "biólogos". Depois, tento determinar o tipo de biologia evolucionária que está em jogo, para poder, num último momento, explorar as ramificações epistemológicas e estéticas do discurso biológico nietzschiano.

Palavras-chave: Nietzsche, Spencer, biologia, epistemologia evolucionista, estética evolucionista, axiologia.

* Universidade de Strasbourg, Strasbourg, França.

ORCID https://orcid.org/0000-0003-0650-4325

Correio eletrônico: emmanuel.salanskis@noos.fr 
Salanskis, E.

Nietzsche fala raramente em "biologia" de modo literal: no conjunto do corpus nietzschiano, constam um pouco menos de trinta ocorrências da palavra e dos seus derivados. Essa constatação pode surpreender se considerarmos a literatura secundária. Com efeito, numerosos trabalhos foram publicados sobre a relação de Nietzsche com a biologia, incluindo monografias, como o pequeno livro de Barbara Stiegler sobre Nietzsche et la biologie (Stiegler, 2001) ou o trabalho mais volumoso de Gregory Moore sobre Nietzsche, Biology and Metaphor, que se tornou um clássico no mundo anglófono (Moore, 2002). No Brasil, Wilson Antonio Frezzatti Jr. também publicou recentemente um artigo intitulado "Nietzsche e a biologia: uma proposta de investigação" (Frezzatti, 2012). De modo geral, a abundância das contribuições sobre o assunto parece ter sido favorecida por um debate recorrente acerca do "biologismo" de Nietzsche. Sabe-se que um dos protagonistas dessa controvérsia tradicional foi Heidegger, que escreveu, no primeiro volume de seu comentário de 1961, que "Nietzsche sem dúvida alguma relaciona tudo [...] com o "biológico"" (Heidegger, 2010, I, p. 478). No entanto, tendo em vista as aspas que figuram na citação de Heidegger, eu gostaria de partir de um problema terminológico: diante da relativa raridade do léxico da biologia em Nietzsche, por que tantos leitores lhe atribuíram uma filosofia biológica, às vezes a ponto de acusá-lo de "biologismo"?

Uma resposta simples vem imediatamente à mente. Etimologicamente, a biologia é a ciência da vida ou dos fenômenos vivos, o que parece incluir conceitualmente uma série de ramos como a anatomia, a fisiologia, a zoologia, a botânica, a embriologia ou a teoria da evolução. Ora, é verdade que Nietzsche mobiliza esses campos disciplinares em sua reflexão filosófica. Se considerarmos a biologia como o conceito unificador que reúne essas diversas disciplinas, pode parecer evidente, portanto, que Nietzsche está 
desenvolvendo uma filosofia "biológica". Esse é aparentemente o raciocínio implícito que foi feito por muitos comentadores.

Mas resta saber se é uma boa maneira de raciocinar. Isso pode ser contestado pelo menos por duas razões: a primeira é que, desse modo, pressupõe-se que a biologia sempre existiu no sentido da disciplina unificada que conhecemos. Contudo, conforme apontou Ernst Mayr, a biologia é uma criança do século XIX (Mayr, 1982, p. 36). Na verdade, tentarei mostrar que o nascimento de uma "biologia" não tinha chegado a seu termo, sob essa denominação explícita, no contexto científico contemporâneo de Nietzsche. A segunda razão é que, neste contexto particular da segunda metade do século XIX, Nietzsche bem poderia usar o vocabulário biológico de um modo que não esperamos. A minha tese geral neste artigo será, de fato, que Nietzsche não entende simplesmente por "biologia" a ciência geral da vida incluindo todas as outras. Seu uso do termo é mais específico e mais interessante. Em última análise, é essa compreensão mais estreita que autoriza Nietzsche a falar de "valores biológicos", como o faz, em particular, no segundo tratado da Genealogia da Moral.

Gostaria de apresentar minha análise em três etapas. Começarei por identificar os interlocutores que Nietzsche designa explicitamente como "biólogos" (I). Depois, tentarei evidenciar, à luz desse uso discursivo, o tipo de biologia que está em jogo (II). E num último momento, explorarei as ramificações epistemológicas e estéticas da perspectiva "biológica" nietzschiana (III).

\section{A "ingenuidade dos biólogos ingleses"}

Uma estratégia simples para discernir o tipo de biologia que Nietzsche tem em mente consiste, primeiro, em identificar seus interlocutores. Quem são os autores que Nietzsche caracteriza como "biólogos", quando usa o termo? 
Salanskis, E.

Sobre esse ponto, uma indicação reveladora é fornecida pela Genealogia da moral, na longa nota que conclui o primeiro tratado. ${ }^{1}$ Nietzsche escreve o seguinte: "O bem da maioria e o bem dos raros são considerações de valor opostas: tomar o primeiro como de valor mais elevado em si, eis algo que deixamos para a ingenuidade dos biólogos ingleses..." (GM/GM I 17 KSA 5.289, trad. PCS). Sabemos que no contexto da Genealogia, essa crítica aos "biólogos ingleses" é particularmente eloquente, na medida em que ecoa as famosas críticas que o livro dirige aos "genealogistas da moral ingleses" (GM/GM, Prefácio 4, KSA 5.251) e aos "psicólogos ingleses" (GM/ GM I 1, KSA 5. 257). Não é necessário supor que se trata de autores diferentes, que são todos ingleses por acaso. Podemos fazer uma leitura muito menos tortuosa. Nietzsche conhece e critica um filósofo inglês que pode reivindicar as três qualificações de psicólogo, biólogo e genealogista da moral: é Herbert Spencer, autor dos Principles of Psychology, dos Principles of Biology e dos Data of Ethics (Spencer, 1855, 1865-1867, 1879). Lembre-se de que Spencer é citado em duas outras passagens da Genealogia da moral (GM/GM I 3, KSA 5.261 e II 12, KSA 5.316), o que confirma que Nietzsche dialoga com o filósofo inglês nessa obra. Pode-se acrescentar que o pensamento de Spencer é claramente visado pela citação reproduzida acima. Com efeito, The Data of Ethics defendem uma ética do bem-estar geral ou "well-being of all" (Spencer, 1879, p. 208, p. 216) que pode, segundo Spencer, ser cientificamente baseada numa doutrina da evolução da vida (p. 61-62). Nietzsche sabe disso, dado que leu o livro em 1880, logo após sua publicação. Assim, quando Nietzsche fala dos "biólogos ingleses", por mais surpreendente que pareça, ele se refere em primeiro lugar a Spencer. Aliás, essa leitura é confirmada por um fragmento póstumo de 1888 onde Nietzsche declara: "O Sr.

1 A tradução do alemão Abhandlung por "dissertação" é um erro frequente que provavelmente se espalhou nas línguas românicas a partir da tradução francesa de Henri Albert, publicada em 1900. Na verdade, Abhandlung não corresponde em alemão a um simples exercício escolar, mas, ao contrário, a um trabalho acadêmico no sentido pleno da palavra.

114 | Cad. Nietzsche, Guarulhos/Porto Seguro, v.42, n.1, p. 111-128, janeiro/abril, 2021. 
Spencer é um décadent enquanto biólogo" (Nachlass/FP, 1888, 14 [40], KSA 13.238, trad. ES).

Spencer biólogo: isso pode soar como uma caracterização muito estranha de um ponto de vista contemporâneo. Hoje, não descreveríamos mais um filósofo como "biólogo", mesmo que ele tivesse escrito Princípios de biologia. A biologia se tornou uma ciência profissional, que ocupa um espaço disciplinar diferente do da filosofia. Mas esse processo de emergência disciplinar, justamente, não foi concluído na segunda metade do século XIX. Ainda que a biologia tivesse sido definida já em 1802 por Lamarck e Treviranus, naquela época, ela correspondia essencialmente a um projeto teórico (Lamarck, 1802; Treviranus, 1802). É verdade que na esteira dessa cunhagem, a palavra Biologie foi usada bastante comumente por cientistas alemães. Por exemplo, em suas palestras de 1868 sobre a História natural da criação, Haeckel menciona a biologia em várias ocasiões, definindo-a como "a ciência da natureza orgânica [...], que tem por objeto de conhecimento os animais enquanto zoologia e as plantas enquanto botânica" (Haeckel, 1868, p. 4, trad. ES). Mas a palavra não é tudo: ela não garante a existência institucional de uma ciência. Enquanto disciplina, a biologia não havia sido realmente implantada na Alemanha até o final do século XIX, como Lynn Nyhart bem mostrou em The Rise of the Biological Perspective in Germany (Nyhart, 2009, p. 22). A relevância dessa observação aparece quando nos referimos às fontes atestadas de Nietzsche no campo das ciências da vida: não são professores de biologia. Oscar Schmidt ensinava a zoologia na Universidade de Estrasburgo (Schmidt, 1873); Wilhelm Roux era Privatdozent no Instituto Anatômico de Breslau (Roux, 1881); Carl von Nägeli era professor de botânica na Universidade de Munique (Nägeli, 1884); William Rolph era Privatdozent de zoologia na Universidade de Leipzig, depois de um doutorado de entomologia (Rolph, 1884); Gustav Bunge era professor de fisiologia 
Salanskis, E.

na Universidade da Basileia (Bunge, 1886). ${ }^{2}$ Podemos ainda ir mais longe ao observar que, nessa lista, o único autor que invoca expressamente a biologia no título do seu livro, William Rolph, quer, na verdade, dialogar com Spencer. Rolf explica isso claramente no prefácio dos seus Biologische Probleme: originalmente, ele queria apenas criticar The Data of Ethics, opondo-lhes um ponto de vista realmente científico (Rolph, 1884, p. iii).

Assim, designar Spencer como biólogo é muito menos estranho do que parece à primeira vista e em retrospecto. $\mathrm{O}$ filósofo inglês era efetivamente uma figura importante do discurso biológico do século XIX. Ele era inclusive um dos poucos autores a usar esse vocabulário extensivamente. E seria anacrônico imaginar que ele ocupava uma posição puramente externa à ciência. Pelo contrário, ele foi citado respeitosamente por Darwin em The Descent of Man (Darwin, 1871, vol. 1, especialmente p. 101); ele recebeu conselhos de Huxley e Hooker ao escrever seus Princípios de biologia (Spencer, 1865, Preface); e outros cientistas, como Rolph, fizeram o esforço de respondê-lo publicamente, embora essa resposta tenha sido frequentemente crítica.

\section{O problema biológico-evolucionário do valor dos valores}

Isso posto, passo agora à questão de que tipo de biologia está em jogo. Se Nietzsche quer criticar Spencer enquanto biólogo, então ele também entende por "biologia" algo mais específico do que a soma indiferenciada das ciências da vida: este é o segundo ponto que gostaria de destacar.

Comecemos por recordar esquematicamente como Spencer concebia sua biologia. Ele a apresentava como resolutamente

2 Além da fisiologia alemã, Nietzsche também conhecia a psicofisiologia francesa do século XIX: sobre esse assunto, remetemos ao estudo de Wilson Frezzatti citado em bibliografia (Frezzatti, 2019).

116 | Cad. Nietzsche, Guarulhos/Porto Seguro, v.42, n.1, p. 111-128, janeiro/abril, 2021. 
evolucionária, uma vez que os Princípios de biologia pretendiam evidenciar as "leis da evolução" que governam todo o mundo vivo. ${ }^{3}$ Mas, por outro lado, o objetivo fundamental de Spencer não era outro senão fundar uma ética nesta biologia: como ele próprio admite, este é o horizonte último do seu sistema filosófico, o que o levou a antecipar a publicação dos Data of Ethics em relação ao plano inicialmente previsto, para poder colher os frutos do seu trabalho mais rapidamente (Spencer, 1879, p. iii). Spencer estava, portanto, mais especificamente interessado na ética que supostamente resulta de uma biologia da evolução. Essa é exatamente a abordagem adotada pelos Biologische Probleme de William Rolph: o título completo é Biologische Probleme, zugleich als Versuch zur Entwicklung einer rationellen Ethik. ${ }^{4}$ Conforme esse título, Rolph também propunha desenvolver uma "ética racional" baseada em considerações sobre a evolução biológica (Rolph, 1884, p. 3).

Mesmo que com uma intenção muito diferente, quando Nietzsche questiona o "valor biológico" de certos afetos, ele investe deliberadamente nesse campo discursivo. Ele o faz, é claro, no quadro da problemática axiológica definida pelo prefácio da Genealogia da moral: trata-se de colocar em questão o valor dos valores morais (GM/ GM, Prefácio 6, KSA 5.253). Contudo, para orientar tal questionamento axiológico, é preciso de um critério de avaliação. E o critério que Nietzsche mobiliza tem uma dimensão biológico-evolucionária. De fato, Nietzsche busca determinar se os valores morais e, por conseguinte, também os impulsos e afetos nos quais esses valores se traduzem, "obstruíram ou favoreceram até agora o prosperar da humanidade" (GM/GM, Prefácio 3, KSA 5.250, trad. RRTF). Esse "prosperar" (Gedeihen) da vida humana deve ser medido numa escala temporal ampla, o que leva Nietzsche a remontar pelo menos

3 "The aim of this work is to set forth the general truths of Biology as illustrative of, and as interpreted by, the laws of Evolution" (Spencer, 1865, Preface).

4 Literalmente: Problemas biológicos, ao mesmo tempo como tentativa para fundar uma ética racional. 
à pré-história no contexto do segundo tratado. Em outras palavras, estamos diante de uma temporalidade de tipo evolucionária, que não se reduz mais à de uma história cultural ordinária, embora Nietzsche seja obviamente também um historiador da cultura.

Podemos agora considerar desse ponto de vista o $§ 11$ do segundo tratado, que é o texto em que Nietzsche invoca claramente um vocabulário biológico contra a concepção de justiça de Eugen Dühring. Vou primeiro relembrar brevemente essa concepção: segundo Dühring, a justiça procede do ressentimento, concebido como uma necessidade natural de vingança que surge em reação a um dano sofrido. Assim, o ressentimento aparece como moralmente legítimo, enquanto afeto que reage a uma transgressão ou violação anterior (Dühring, 1875, p. 224). E pode-se dizer nessa perspectiva que a própria justiça é uma forma de vingança. Isso significa que Dühring opera uma espécie de reabilitação dos afetos reativos. Mas, paralelamente a essa apologia e como se fosse seu corolário, Dühring desvaloriza ainda mais fortemente outra categoria de afeto: o que ele chama de "paixões ruins" (schlechte Leidenschaften). Fato notável, essas paixões são descritas em referência ao animal de rapina, o Raubthier, o que parece muito interessante de um ponto de vista nietzschiano. A passagem do Cursus der Philosophie citada abaixo ilustra bem esse discurso:

Temos que procurar as paixões realmente ruins na voracidade (Raubgier) e no apetite de dominação (Herrschsucht), isto é, nesta configuração particular de impulsos falsos que encontramos realizados no animal de rapina (Raubthier). A repressão e exploração do homem pelo homem são baseadas nessas paixões realmente ruins.

O juízo moral de Dühring é evidente aqui: comportar-se como um predador é mau e até bestial, enquanto a vingança, que responde a um comportamento predatório, já é muito mais aceitável.

Porém, a biologia antispenceriana de Nietzsche vem colocar em questão esse dualismo das boas e das más paixões. É importante 
notar que Nietzsche não se opõe a uma reabilitação parcial dos afetos reativos: o próprio autor da Genealogia da moral sugere que "tendo em vista o problema biológico no seu todo", "o valor desses afetos foi até hoje subestimado" (GM/GM II 11, KSA 5.310, trad. PCS). Já sabemos que para o genealogista nietzschiano, o "problema biológico" em questão é o do florescimento durável da vida humana. É nessa perspectiva que se deve fazer a Dühring uma objeção fundamental: os chamados "maus impulsos" do predador são, na verdade, "de valor biológico bem mais elevado" (GM/GM II 11, KSA 5.310, trad. PCS). Dühring cometeu uma injustiça caracterizada contra o Raubthier, na esteira da moral judaico-cristã, que ignorou tipicamente uma realidade biológica essencial. Os impulsos agressivos denunciados hoje como imorais foram produzidos e preservados por milhões de anos de evolução. ${ }^{5}$ Se esses impulsos nos foram transmitidos, é provável que eles tenham contribuído para a conservação da nossa espécie, pelo menos na mesma medida que os instintos que chamamos de "bons". Pode-se citar o primeiro parágrafo da Gaia ciência a esse respeito:

O ódio, a alegria com o mal alheio, a ânsia de rapina e domínio e tudo o mais que se chama de mau: tudo é parte da assombrosa economia da conservação da espécie, certamente uma economia pródiga, dispendiosa e, no conjunto, extremamente insensata: - mas que, de modo comprovado, até o momento conservou nossa estirpe (FW/GC 1, KSA 3.369-370, trad. PCS).

"De modo comprovado": ou seja, o fato de ter subsistido numa escala temporal tão vasta é uma prova de viabilidade sólida, muito mais confiável do que poderia oferecer uma moral que mal tem 2000 anos.

Em vista desses elementos, não é exagero dizer que Nietzsche reabilita a agressão até certo ponto, assim como Dühring tinha

5 Em termos de escala cronológica, Nietzsche fala apenas de milhões de anos de evolução e ainda não de bilhões, como os pensadores evolucionistas da segunda metade do século 19: veja Nachlass/ FP, 1876, 23 [9], KSA 8.405. 
sido o advogado da vingança. Ao mesmo tempo, é uma maneira de responder a Spencer. Pois os Data of Ethics defendiam uma visão manifestamente moral da evolução: Spencer contava a longa história do progresso evolutivo dos comportamentos, dos infusórios até o homem, profetizando uma reconciliação futura do egoísmo e do altruísmo, graças ao advento de uma sociedade industrial totalmente pacífica e cooperativa (Spencer, 1879, p. 169). Nesse grande afresco comportamental, a moralidade aparecia como uma adaptação gradual à vida em sociedade e a agressividade como um retardamento evolutivo: agressões humanas eram um resto de vida selvagem "inteiramente predatória", nas palavras de Spencer (Spencer, 1879, p. 18, trad. ES). Mas a Genealogia da moral inverte completamente essa perspectiva axiológico-biológica. Para Nietzsche, uma vida sem agressividade teria sido totalmente incapaz de preservar-se e de crescer. Seria precisamente uma não-vida, a fortiori se admitirmos a hipótese da vontade de potência: de fato, se a vida é vontade de potência, então ela é essencialmente uma dinâmica de expansão e apropriação, pelo menos na forma da nutrição, do crescimento e da reprodução. Nesse sentido, a ética evolucionista de Spencer bem poderia naturalizar uma moral "hostil à vida" (lebensfeindlich), para usar um termo nietzschiano característico. Daí a ideia, no fragmento póstumo já citado, de que Spencer está decadente enquanto biólogo.

\section{A reinterpretação nietzschiana da epistemologia e da estética}

Vou me limitar a essas indicações no que diz respeito ao questionamento biológico que Nietzsche aplica à moral. Na última parte deste artigo, gostaria de mostrar que Nietzsche faz o mesmo trabalho em relação à teoria do conhecimento e à estética, usando, de novo, um vocabulário explicitamente biológico. A lógica permanece fundamentalmente a mesma: para Nietzsche, colocar um problema biológico significa colocar um problema de valor do ponto de vista 
geral da evolução da vida ou do ponto de vista mais particular do florescimento humano.

Começo por considerar os fragmentos póstumos que usam uma terminologia biológica acerca da teoria do conhecimento. $\mathrm{Na}$ verdade, esse é um aspecto para o qual Heidegger já chamou a atenção em seu famoso comentário, dedicando uma seção inteira à "interpretação 'biológica' do conhecimento dada por Nietzsche" (Heidegger, 2010, vol. 1, p. 459-467). Mas não vou seguir a leitura de Heidegger, pois sua marca distintiva, a meu ver, é acrescentar aspas indevidas ao adjetivo "biológico", para defender a ideia de que o biológico nietzschiano não é propriamente biológico: como se existisse tal próprio, de modo geral ou a fortiori na época de Nietzsche. Essa pressuposição já foi rejeitada na primeira parte do meu artigo e não voltarei a esse ponto aqui. Por sua vez, Nietzsche se abstém de aspas, o que significa que ele não apresenta sua linguagem como especialmente metafórica (embora qualquer linguagem seja uma interpretação tecida de tropos retóricos aos olhos de Nietzsche). Assim, a chave de leitura da metáfora não abre nenhuma porta aqui e devemos examinar os textos com atenção para tentar entender sua lógica.

Um dos textos mais claros para compreender a teoria do conhecimento biológica de Nietzsche é o fragmento 14 [153] de 1888. Nesse texto, trata-se mais exatamente de uma teoria da cognição, como explicarei em breve. $\mathrm{O}$ fragmento começa do modo seguinte:

O erro da filosofia reside no fato de que, em vez de ver na lógica e nas categorias da razão meios de organizar o mundo para fins de utilidade (isto é, no plano "principial", para operar uma falsificação útil), pensamos que tínhamos nelas o critério da verdade ou melhor, da realidade. $\mathrm{O}$ "critério da verdade" era somente, na realidade dos fatos, a utilidade biológica de tal sistema de falsificação principial: e uma vez que uma espécie animal não conhece nada mais importante que sua preservação, efetivamente, tínhamos o direito de falar aqui de "verdade". A ingenuidade era apenas tomar a idiossincrasia antropocêntrica como medida das coisas, como norma 
Salanskis, E.

do "real" e do "irreal": era, em resumo, absolutizar uma condicionalidade (Nachlass/FP, 1888, 14 [153], KSA 13.336, trad. ES).

Temos aqui uma exposição suficientemente clara e concisa da posição nietzschiana. Encontramos nesse contexto o que alguns comentadores chamaram de "tese de falsificação": ou seja, a ideia de que o nosso aparelho cognitivo esquematiza a realidade para poder interpreta-la de forma mais eficaz, o que equivale a distorcê-la ou mesmo a falsificá-la (Riccardi, 2013). Sem entrar em detalhes a respeito dessa teoria no contexto do presente artigo, gostaria apenas de focalizar-me em sua dimensão biológica. Falsificar a realidade como fazemos tem, no entender de Nietzsche, uma "utilidade biológica": segundo um outro fragmento póstumo de 1888, é até uma "restrição biológica" (biologische Nöthigung) para os animais que somos (Nachlass/FP, 1888, 14 [152], KSA 13.334, trad. ES).

Como interpretar tal afirmação? Com esse discurso, Nietzsche ecoa um tipo de análise que ele conhecia por suas leituras e que apareceu alguns anos depois da publicação, em 1859, da primeira edição de A origem das espécies de Darwin. São as primeiras epistemologias evolucionistas. Elas se desenvolveram especialmente na Alemanha, onde a herança kantiana era muito forte: alguns leitores de Darwin propuseram reinterpretar as estruturas a priori do conhecimento como uma hereditariedade cognitiva que resultaria da evolução por seleção natural. Era, portanto, uma forma de naturalização do a priori kantiano, que implicava tratá-lo como a posteriori do ponto de vista da espécie. Haeckel, por exemplo, defendeu essa concepção em sua História natural da criação (Haeckel, 1868, p. 26-27). Mas ela foi também adotada por filósofos, como Eduard von Hartmann, que contribuiu para divulgá-la em sua Filosofia do inconsciente (Hartmann, 1877, p. 155). Observe-se que essa doutrina epistemológica tem implicações "limitacionistas", no sentido de limitar as pretensões transcendentais do conhecimento a priori. Como Konrad Lorenz argumentará no século XX, o a priori nada mais é, para o biologische Erkenntnistheoretiker, do 
que um conjunto de "hipóteses de trabalho" hereditárias que poderiam revelar-se injustificadas (Lorenz, 1941). Nietzsche se inscreve nessa tradição, destacando, também ele, que não se pode mais "absolutizar uma condicionalidade". Ao mesmo tempo, ele admite que há um interesse biológico em validar os esquemas interpretativos que garantiram nossa conservação até agora. Essa estratégia certamente tem uma relevância pragmática, desde que mantenhamos uma certa desconfiança perspectivista em relação à nossa própria cognição. Devemos ter consciência de que o nosso a priori nunca é mais do que uma perspectiva situada, uma "idiossincrasia antropocêntrica" que não nos permite aceder a uma realidade em si, mas que, no melhor caso, serve a nossa vontade de potência.

Não insisto mais na teoria do conhecimento biológica de Nietzsche e imediatamente me volto para sua estética. Aqui, a biologia nietzschiana assume de novo a forma de uma interpretação evolucionista, desta vez acerca do sentimento de beleza e feiura. Esse aspecto é particularmente visível num fragmento póstumo de 1887 intitulado "Aesthetica", cujo início eu cito abaixo:

Sobre a emergência do belo e do feio. O que instintivamente nos resiste, esteticamente, é aquilo que, a partir de uma longuíssima experiência, provou ser algo danoso, perigoso, suspeitoso para o homem: o instinto estético que passa a tomar a palavra de imediato (por exemplo no desgosto) contém um juízo. Nessa medida, o belo pertence à categoria geral dos valores biológicos de proveitoso, benéfico, intensificador de vida [...]. (Nachlass/FP, 1887, 10 [167], KSA 12. 554, trad. ES).

Vemos aqui que Nietzsche estende a noção de "valores biológicos" além da categoria de utilidade. Na verdade, a hipótese da vontade de potência não é um mero utilitarismo. Ela implica que a vida tende, de modo geral, a intensificar sua potência, o que é algo mais do que uma conservação spinoziana, schopenhaueriana ou spenceriana. O conceito de resistência ganha sentido neste contexto. Em sua dinâmica de expansão, a vontade de potência encontra resistências 
que ela interpreta e busca superar. Isso implica que sempre existem oportunidades de crescimento ou ameaças de enfraquecimento. Ora, é aqui que Nietzsche traz o belo e o feio, enquanto sinalizações evolucionárias $^{6}$. Com efeito, as oportunidades e as ameaças nem sempre estão imediatamente presentes para nossa percepção sensível. Por isso, o nosso organismo também aprendeu a orientar-se: ele é capaz de localizar à distância, temporal ou espacialmente, grupos de estímulos que anunciam uma oportunidade ou uma ameaça. Como o resto do fragmento explica, a beleza designa assim "um conjunto de excitações que lembram, muito distantemente, coisas e estados úteis" (Nachlass/FP, 1887, 10 [167], KSA 12. 554, trad. ES). ${ }^{7} \mathrm{O}$ ponto essencial, aqui, é aquele que Nietzsche acrescenta entre parênteses: “(- não apenas as coisas, mas também os sentimentos que as acompanham ou seus símbolos)". Ou seja, o belo não precisa ser imediatamente útil ou revigorante. Em vez disso, ele é uma promessa de utilidade ou de crescimento, um símbolo que é reconhecido pelo organismo de longe. Foi certamente nesse sentido que Nietzsche pôde apropriar-se da frase de Stendhal: "a beleza [...] é apenas uma promessa de felicidade" (GM/GM III 6, KSA 5.347, trad. PCS). Na verdade, basta substituir "felicidade" por "intensificação do sentimento de potência" para nietzscheanizar a fórmula.

Essas breves observações mostram que Nietzsche desenvolveu uma estética evolucionária paralela à sua epistemologia biológica. Conforme indicado num fragmento de 1888, essa teoria estética tinha um duplo princípio fundamental: que "os valores estéticos são baseados em valores biológicos" e que "os sentimentos de bem-estar estético são sentimentos de bem-estar biológico" (Nachlass/FP, 1888, 16 [75], KSA 13.511, trad. ES). De resto, pode-se pensar que esses dois axiomas subjazem à patologização da figura de Wagner em $O$

6 Interpretações mais contemporâneas da beleza como sinalização foram desenvolvidas no contexto da estética evolucionária (Watanabe, 2015, p. 290-291).

7 Poderíamos até acrescentar: ou oportunidades de crescimento.

124 | Cad. Nietzsche, Guarulhos/Porto Seguro, v.42, n.1, p. 111-128, janeiro/abril, 2021. 
caso Wagner: não é por acaso que o epílogo reafirma que "a estética se acha indissoluvelmente ligada a [...] pressupostos biológicos" (WA/ CW, Epílogo, KSA 6.50, trad. PCS). E tudo o que Nietzsche chama de "fisiologia da arte" nos escritos de 1888 parece participar da mesma problemática evolucionária, como Gregory Moore bem mostrou em Nietzsche, Biology and Metaphor (Moore, 2002, p. 85-111).

\section{Conclusão}

Concluo esta apresentação sucinta. Nietzsche elabora um discurso biológico em relativamente poucos textos e em um sentido mais específico do que o da biologia como categoria geral unificadora. A abordagem nietzschiana parece mais com o que Lynn Nyhart chama de "biologia no sentido estreito": ou seja, uma perspectiva funcional e evolutiva, que estuda as relações dos organismos com seu meio ambiente (Nyhart, 2009, p. 21). Esse também é o tipo de biologia que Spencer tinha praticado antes de Nietzsche, embora as conclusões dos dois autores sejam diametralmente opostas. Faz sentido falar de "valores biológicos" nesse contexto. Aliás, seria preciso perguntar-se se essa ideia não teve uma vasta posteridade no século XX, por exemplo em Canguilhem, que usará a mesma expressão várias vezes em $O$ normal e o patológico (Canguilhem, 2009, por exemplo p. 88).

Seja como for, em Nietzsche, todos os valores estão ligados à dinâmica da vontade de potência. São condições de vida e de crescimento que um organismo experimenta na forma de preferências. Tais preferências estão em ação em todas as áreas, da moralidade à estética, passando pela epistemologia. Daí, evidentemente, a acusação recorrente de "biologismo". Mas o que essa acusação parece ignorar é que não existe apenas uma biologia e que, portanto, a questão não é apenas delimitar a extensão "própria" do reino biológico. Como tentei mostrar, Nietzsche defende uma biologia contra outras biologias, um reducionismo da vontade de potência contra outros reducionismos. Em 
outras palavras, parece-me necessário superar a falsa alternativa do próprio e do figurado na qual Heidegger aprisionou a problemática biológica de Nietzsche. Mais uma vez, como sugeriu Scarlett Marton em sua "irrecusável busca de sentido", a via proposta por Heidegger "não [dá] conta da riqueza da filosofia nietzschiana" (Marton, 2004, p. 141-142).

\title{
The notion of biological values in Nietzsche
}

\begin{abstract}
This paper aims at clarifying the concrete use Nietzsche makes of the biological vocabulary in his work. Instead of conceiving biology as the undifferentiated sum of the life sciences, which is an anachronism in view of the fragmented situation of these sciences in the second half of the 19th century, I take into consideration Lynn Nyhart's work on the rise of the biological perspective in Germany, to highlight the narrower sense in which Nietzsche speaks of "biology". The first part of the paper identifies the interlocutors Nietzsche explicitly characterizes as "biologists". I then try to ascertain the type of evolutionary biology that is at stake, to be able, in a last moment, to explore the epistemological and aesthetic ramifications of the Nietzschean biological discourse.
\end{abstract}

Keywords: Nietzsche, Spencer, biology, evolutionary epistemology, evolutionary aesthetics, axiology.

\section{Referências}

BUNGE, G. Vitalismus und Mechanismus. Leipzig: Verlag von F. C. W. Vogel, 1886.

CANGUILHEM, G. O normal e o patológico. Trad. Maria Thereza Redig de Carvalho Barrocas. Rio de Janeiro/São Paulo: Editora Forense Universitária, 2009.

DÜHRING, E. Cursus der Philosophie als streng wissenschaftlicher Weltanschauung und Lebensgestaltung. Leipzig: Erich Koschny, 1875.

126 | Cad. Nietzsche, Guarulhos/Porto Seguro, v.42, n.1, p. 111-128, janeiro/abril, 2021. 
FREZZATTI JR., W. Nietzsche e a biologia: uma proposta de investigação. In: Dutra de Azeredo, V.; Da Silva Júnior, I. (orgs.). Nietzsche e a interpretação. Curitiba/São Paulo: CRV, 2012, p. 177-194. 2019.

. Nietzsche e a psicofisiologia francesa do século XIX. São Paulo: Humanitas,

Haeckel, E. Natürliche Schöpfungsgeschichte. Gemeinverständliche Vorträge über die Entwicklungslehre im Allgemeinen und diejenige von Darwin, Goethe und Lamarck im Besonderen. Berlin, G. Reimer, 1868.

HaRtManN, E. (von). Das Unbewusste vom Standpunkt der Physiologie und Descendenztheorie. Berlin, C. Duncker Verlag, 1877.

HEIDEGGER, M. Nietzsche. Trad. Marco Antônio Casanova. Rio de Janeiro: Editora Forense Universitária, 2010, 2 vol.

Lamarck, J.-B. (de). Hydrogéologie. Paris: Agasse et Maillard, 1802.

LORENZ, K. Kants Lehre vom Apriorischen im Lichte gegenwärtiger Biologie. In : Blätter für Deutsche Philosophie. N$^{\circ}$ 15, 1941, p. 94-125.

MARTON, S. A irrecusável busca de sentido. Autobiografia intelectual. Ijuí: Editora UNIJUÍ, 2004.

MAYR, E. The Growth of Biological Thought: Diversity, Evolution, and Inheritance, Cambridge/London: Harvard University Press, 1982.

MOORE, Gr. Nietzsche, Biology and Metaphor. Cambridge: Cambridge University Press, 2002.

NÄGELI, C. (von). Mechanisch-physiologische Theorie der Abstammungslehre. München/Leipzig: Druck und Verlag von R. Oldenbourg, 1884.

NIETZSCHE, Fr. Genealogia da moral. Trad. Paulo César de Souza. São Paulo: Companhia das Letras, 1998.

. O Caso Wagner/Nietzsche contra Wagner. Trad. Paulo César de Souza. São Paulo: Companhia das Letras, 1999.

. Sämtliche Werke. Kritische Studienausgabe. Berlin/New York: Walter de Gruyter, 1999, 15 vol. 
Salanskis, E.

. A gaia ciência. Trad. Paulo César de Souza. São Paulo: Companhia das Letras, 2001.

Nyhart, L. Modern Nature: The Rise of the Biological Perspective in Germany. Chicago/London: The University of Chicago Press, 2009.

RICCARDI, M. Nietzsche und die Erkenntnistheorie und Metaphysik. In : HEIT, H.; Heller, L. (Hrsg.). Handbuch Nietzsche und die Wissenschaften: Natur-, geistes- und sozialwissenschaftliche Kontexte. Berlin/New York: Walter de Gruyter, 2013, p. 242-264.

ROLPH, W. Biologische Probleme zugleich als Versuch zur Entwicklung einer rationellen Ethik. Leipzig: Verlag von Wilhelm Engelmann, 1884.

ROUX, W. Der Kampf der Theile im Organismus. Ein Beitrag zur Vervollständigung der mechanischen Zweckmässigkeitslehre. Leipzig: Verlag von Wilhelm Engelmann, 1881.

Schmidt, O. Descendenzlehre und Darwinismus. Leipzig: F. A. Brockhaus, 1873.

SPENCER, H. Principles of Psychology. London: Longman, Brown, Green, and Longmans, 1855.

. Principles of Biology. London: Williams and Norgate, 2 vol., 1865-1867.

. The Data of Ethics. London: Williams and Norgate, 1879.

STIEGLER, B. Nietzsche et la biologie. Paris: PUF, 2001.

TREVIRANUS, G. R. Biologie, oder Philosophie der lebenden Natur für Naturforscher und Aerzte. Göttingen: Johann Friedrich Röwer, 1802.

WATANABE, Sh. Aesthetics and Reinforcement: a Behavioural Approach to Aesthetics. In: HOQUET, Th. (ed.). Current Perspectives on Sexual Selection. What's Left After Darwin?. Dordrecht: Springer, 2015, p. 289-307.

Enviado: $12 / 08 / 2020$

Aceito: 08/10/2020

128 | Cad. Nietzsche, Guarulhos/Porto Seguro, v.42, n.1, p. 111-128, janeiro/abril, 2021. 